\title{
ERRATUM
}

\section{Outcome of children with high-risk acute myeloid leukemia given autologous or allogeneic hematopoietic cell transplantation in the AIEOP AML-2002/01 study}

F Locatelli, R Masetti, R Rondelli, M Zecca, F Fagioli, A Rovelli, C Messina, E Lanino, A Bertaina, C Favre, G Giorgiani, M Ripaldi, O Ziino, G Palumbo, M Pillon, A Pession, S Rutella and A Prete on behalf of AIEOP BMT Working Group

Bone Marrow Transplantation (2015) 50, 320; doi:10.1038/bmt.2014.291

Correction to: Bone Marrow Transplantation advance online publication, 10 November 2014; doi:10.1038/bmt.2014.246

Since the publication of this article the authors have noted a number of errors.

The abbreviations 'CHOP' and 'BEAM' should be replaced by 'cyclophosphamide' and 'melphalan' throughout the article.

The second sentence of the abstract on Page 1 should read:

All patients received a myeloablative regimen combining busulfan, cyclophosphamide and melphalan; AUTO-HSCT patients received $\mathrm{BM}$ cells in most cases, while in children given
ALLO-HSCT stem cell source was BM in 96, peripheral blood in 19 and cord blood in 26.

The first sentence of the paragraph entitled 'Conditioning regimen and GVHD prophylaxis' on Page 3 should read:

The conditioning regimen was homogenous in all the patients and it consisted of a combination of busulfan (BU, $16 \mathrm{mg} / \mathrm{kg}$ over 4 days), cyclophosphamide (CY, $120 \mathrm{mg} / \mathrm{kg}$ divided in two doses) and melphalan (L-PAM, $140 \mathrm{mg} / \mathrm{m}^{2}$ ).

In Table 3 on Page 6, under the Variable column, the second last subheading aGVHD should be replaced by cGVHD

The corrected article appears in this issue together with this corrigendum. The publisher wishes to apologize for any inconvenience caused. 